International Journal of Medical Sciences

ISSN 1449-1907 www.medsci.org 2007 4(5):278-287

Research Paper

(C) Ivyspring International Publisher. All rights reserved

\title{
Self-rated health showed a consistent association with serum HIDL-cholesterol in the cross-sectional Oslo Health Study
}

\author{
Sissel E. Tomten ${ }^{1}$ and Arne T. Høstmark² \\ 1. Norwegian School of Sport and Physical Education, Box 4014 Ullevål Hageby, 0806 Oslo, Norway \\ 2. University of Oslo, Norway, Section of Preventive Medicine and Epidemiology, Box 1130 Blindern, 0318 Oslo, Norway
}

Correspondence to: Sissel E. Tomten, PhD, The Norwegian School of Sport and Physical Education, PO Box 4014 Ullevål Hageby, 0806 Oslo, Norway. Tlf : +47 232623 69; Fax: +47 232624 51; e-mail: sissel.tomten@nih.no

Received: 2007.05.03; Accepted: 2007.11.16; Published: 2007.11.20

Objective: To examine the association between serum HDL-cholesterol concentration (HDL-C) and self rated health (SRH) in several age groups of men and women.

Study design and setting: The study had a cross-sectional design and included 18,770 men and women of the Oslo Health Study aged 30; 40 and 45; 69-60; 75-76 years.

Results: In both sexes and all age groups, SRH (3 categories: poor, good, very good) was positively correlated with HDL-C. Logistic regression analysis on dichotomized values of SRH (i.e. poor vs. good health) in each age group of men and women showed that increasing HDL-C values were associated with increasing odds for reporting good health; the odds ratio (OR) was highest in young men, and was generally lower in women than in men. Odds ratios in the 4 age groups of men were 4.94 (2.63-9.29), 2.25 (1.63-3.09), 2.12 (1.58-2.86), 1.87 (1.37-2.54); and in women: 3.58 (2.46-5.21), 2.81 (2.23-3.53), 2.28 (1.84-2.82), 1.61 (1.31-1.99). In the whole material, $1 \mathrm{mmol} / \mathrm{L}$ increase in HDL-C increased the odds for reporting good health by $2.27(2.06-2.50 ; p<0.001)$, when adjusting for sex, age group, time since food intake and use of cholesterol lowering drugs. Chronic diseases, pain, psychological distress, smoking, alcohol, length of education, and dietary items did not have any major influence on the pattern of the HDL-C vs. SRH association.

Conclusion: There was a consistent positive association between HDL-C and SRH, in both men and women in four different age groups, with the strongest association in young people.

Key words: Health, HDL-C, SRH, epidemiology, biological marker

\section{INTRODUCTION}

The large number of factors influencing self rated health (SRH) would suggest complex explanatory mechanisms which are hard to unravel. Some epidemiological studies suggest, however, that SRH may serve as an indicator for overall health, although it may be influenced by pain [1] and psychological issues [2]. To examine how useful SRH is to predict mortality compared with more traditional indicators, Mossey and Shapiro [3] collected information on SRH, together with physicians' reports based upon objective measures, and did a six years follow-up study on mortality. This investigation showed that subjects who had given themselves a poor health rating had a three times greater risk of dying in the next few years compared with those who had rated their health as excellent. In the study SRH was a more powerful predictor of mortality than the physicians' reports. Furthermore, SHR has been associated with health service utilization [4], future morbidity [5], and with general mortality $[6,7]$.

Other studies suggest that SRH may have a biological basis involving many biomarkers $[8,9]$. As observed in a population sample of 4,065 men and women above 70 years, high density lipoprotein cholesterol (HDL-C) seems to be one of the biomarkers which is positively associated with SRH [8]. However, in cross sectional studies it is hard to appreciate whether associations might be based on a causal relationship. It would appear that many of the single-factor associations with SRH could be explained by relations to a third factor, and that although HDL-C might serve as a health marker, the association between SRH and HDL-C might be weakened and possibly eliminated when adjusting for potential confounders such as gender, age, chronic disease, body mass index, physical activity, and social factors.

The HDL-C vs. SRH-association, as observed in a cross sectional study among elderly people, raises the question of 1) whether a similar relationship exists also in younger age groups, since self rating of health could be modified by age, and 2) if the strength of the association may be weakened or eliminated by the inclusion of possible confounders. The purpose of the present work was to elucidate these questions.

\section{METHODS}

\section{Main project}

In 2000-2001 the Oslo Health Study was 
conducted under the joint collaboration of the National Health Screening Service of Norway (now the Norwegian Institute of Public Health), the University of Oslo and the Municipality of Oslo. The study population included all individuals in Oslo County born in 1970, 1960, 1955, 1940-41 and 1924-25. At the time of the data collection, the subjects were $30,40,45$, $59-60$, or 75 - 76 years of age. A total of 18,770 individuals (45.9\% of the invited) participated.

The responders consisted of 8,404 men $(42.4 \%$ of the invited) and 10,366 women (49.3\% of the invited) who attended the physical examination and/or completed at least one of the questionnaires. The response group did not seem to be related to self-reported health, smoking, BMI or mental health as the participants differed only slightly from estimated prevalence values in the target population [10].

One self-administered questionnaire was part of the letter of invitation, (http://www.fhi.no/dav/366D896093.pdf) whereas two supplementary questionnaires were handed out at the screening units, and sent back in pre-stamped self-addressed envelopes. The questionnaires provided information on health status, symptoms, diseases and various aspects of health related behaviour, and were returned within days of the blood sampling. The specific question about health was: "How would you describe your present state of health?" with four alternatives: 1) 'Poor', 2) 'Not very good', 3) 'Good', and 4) 'Very good'. No definition of "health" was provided. Up to two reminders were sent to non-responders. The second reminder invited those living in the suburban parts of the city to mobile screening units parked in their neighbourhoods.

At the screening unit a simple clinical examination was conducted, and measurements and analyses were performed according to a standard protocol (HUBRO protocol): http:// www.fhi.no/dav/bbb2a86ad7.doc

Non-fasting serum total cholesterol, serum HDL-C, glucose and serum triglycerides were measured directly by an enzymatic method (Hitachi 917 autoanalyzer, Roche Diagnostic, Switzerland). Seronorm Lipoprotein was used as reference material for the lipid analyses and Autonorm Human Liquid for the glucose analyses. The control material was introduced at the start and for every $30^{\text {th }}$ sample. All the laboratory investigations were performed by the Department of Clinical Chemistry, Ullevål University Hospital, Oslo, Norway. The results were registered and transferred on data files to the National Health Screening Service. LDL cholesterol (LDL-C) was estimated using the Friedewald formula [11]. Body weight (in kilograms, one decimal) and height (in cm, one decimal) was measured with electronic Height and Weight Scale with the participants wearing light clothing without shoes.

The study protocol was placed before the Regional Committee for Medical Research Ethics and approved by the Norwegian Data Inspectorate. The study has been conducted in full accordance with the
World Medical Association Declaration of Helsinki.

Of the 18,770 participants of the study there were 17,794 respondents (7,933 males and 9,861 females) with data both on self reported health, serum HDL-C, and triglyceride concentration. The analyses are confined to these subjects.

\section{Statistical analysis}

Due to the relatively small number of subjects reporting 'poor' health (180 men, 243 women) in the material, the health rating alternatives 'poor' and 'not very good' were grouped together as 'Poor', thus forming three groups to be used in the correlation analyses: Poor, Good and Very good. The sex and age distributions of the $3 \mathrm{SRH}$ groups were fairly symmetrical (results not shown). All bi-variate associations were studied using non-parametric correlation analyses. (Rs is used to designate the Spearman correlation coefficient). Multiple comparisons were performed using Kruskal Wallis ANOVA, and Mann-Whitney's test with Bonferronis correction for two group comparisons. No weighting of any of the 'independents' was made, since (graphical) evaluation of the associations between the various 'independents' and the dependent (SRH, 3 groups) were linear (not shown).

Contrasting the subjects which were reporting positive health, with those reporting negative health, was considered a major aspect of the study. Therefore, the variable "SRH" was further dichotomized into "Poor health" (1719 men and 2724 women) and "Good health" (pooling "Good" and "Very good", 6214 men and 7137 women). Logistic regression analysis was carried out on the dichotomized health variable. HDL-C ( $\mathrm{mmol} / \mathrm{L})$ served as the independent variable under special investigation. Several possibly confounding factors were added to the model: sex, age group (1-4), triglycerides (mmol/L), LDL-C (mmol/L), time since the last meal (hours), smoking (never smoked $=0$, current smoker $=1$ ), frequency of alcohol intake (Group 0: $\leq 2-3$ times/week; group 1: $>2-3$ times/week), musculoskeletal pain (see below), mood/psychological distress (see below), length of education (number of years at school), and number of good friends. Body mass index $\left(\mathrm{kg} / \mathrm{m}^{2}\right)$ was used as a continuous variable in Spearman correlation analysis; and dichotomized in logistic regression (group $0=$ $\mathrm{BMI}<30$, group $1=\mathrm{BMI} \geq 30$ ). Other possible confounders in the association between HDL-C and SRH were physical activity level (i.e. the amount of light physical activity at spare time, with 4 alternatives ( no activity, <1h/week, 1-2h/week, $\geq 3 \mathrm{~h} /$ week), and chronic diseases (Group 1:with-; Group 0:without): diabetes; cardiovascular disease (CVD) including myocardial infarction or angina pectoris or stroke; pulmonary diseases including rhinitis or asthma or chronic bronchitis, and "birthplace"; group 0: born in an industrialized country (i.e. Europe or North-America) vs. group 1: born in a developing country (i.e. in Middle- or South-America, Asia, or Africa). Musculoskeletal pain was entered into the model as a Pain index constructed as the sum of pain 
scores at six locations (neck/shoulders; arms/hands; upper back; lower back; hips/legs/feet; other places). For Spearman correlation analysis, the Pain index is presented with 6 values representing the scores $=6,6-8$, $8-10,10-12,12-14$, and >14; where increasing values would be an estimate of pain severity and/or pain distribution in the body. In logistic regression, a dichotomized variable was used: group 0: no reported musculoskeletal pain group 1: pain in one or more of the locations referred above. The Mood index was calculated as the sum of scores on 10 questions (dealing with: fear, anxiety, dizziness, tension, self blame, insomnia, depression, a feeling of uselessness, and hopelessness, and that everything was a burden,). For Spearman correlation, the Mood index is presented with 6 values representing the scores 10, 10-15, 15-20, 20-25, 25-30, and >30. High Mood index values indicate a highly negative psychological state. We did not consider in more detail the psychometric characteristics of the Mood index, which possibly might have been improved e.g. by weighting the contribution of some of its components. In logistic regression, a dichotomized Mood variable was used; group $0=$ none of the above mood complaints; group 1: one or more of the complaints present.

In all the logistic regression analyses, time since last food intake and use of cholesterol lowering drugs were controlled for, and separate logistic regression analyses were performed according to sex and age-group (Table 3). As pointed out earlier [12] covariates in the 'causal path' should not be simultaneously included as independents. It cannot be ruled out that some covariates, such as diabetes, physical activity and intake frequency of alcohol, might be causally associated with HDL-C. It would, on the other hand, seem difficult to define which factors are internal and external in a hypothetical causal pathway from HDL-C to SRH. Therefore, we first included only HDL-C, and after that, separately added one by one of the independents listed above when performing the logistic regression analyses between HDL-C and SRH (Table 3). The significance level was set to $\alpha=0.001$ due to multiple analyses. SPSS 15.0 was used for the statistical analyses and Sigma Plot 2001 for producing the figures.

\section{RESULTS}

\section{Some basic data}

In the material 3.0\% reported diabetes, $2.7 \%$ had a history of myocardial infarction, $2.9 \%$ of stroke, and 4.0 $\%$ reported chronic bronchitis, and $14.8 \%$ reported psychiatric problems. There were $25.8 \%$ smokers; $71.1 \%$ were employed, $5.8 \%$ on sick leave, $9.3 \%$ were disabled pensioners. Of the total group $12.2 \%$ were on treatment for hypertension, and $7.1 \%$ were using cholesterol lowering drugs.

\section{Distribution of participants by self-rated health, sex, and age group}

There was a significant decrease in SRH with increasing age group, and each of the groups had a rating on health that was significantly different from all other groups $(p<0.001)$. A majority of the participants reported good health (Table 1, middle columns), but the percentage decreased somewhat with increasing age. In general, men reported significantly better health than women $(p<0.001)$.

Table 1. Distribution of participants by self-rated health (SRH), sex and age group

\begin{tabular}{|c|c|c|c|c|c|c|c|}
\hline \multicolumn{4}{|c|}{ Men } & \multicolumn{4}{|c|}{ Women } \\
\hline Agegroup & SRH & $\mathbf{n}$ & Percent & Agegroup & SRH & $\mathbf{n}$ & Percent \\
\hline \multirow{4}{*}{ Young } & Poor & 171 & 9,6 & Young & Poor & 316 & 14,5 \\
\hline & Good & 1117 & 62,5 & & Good & 1204 & 55,3 \\
\hline & Very good & 498 & 27,9 & & Very good & 657 & 30,2 \\
\hline & Total & 1786 & 100,0 & & Total & 2177 & 100,0 \\
\hline \multirow{4}{*}{ Middle-aged } & Poor & 567 & 20,1 & Middle-aged & Poor & 781 & 22,2 \\
\hline & Good & 1638 & 58,2 & & Good & 1883 & 53,6 \\
\hline & Very good & 611 & 21,7 & & Very good & 848 & 24,1 \\
\hline & Total & 2816 & 100,0 & & Total & 3512 & 100,0 \\
\hline \multirow[t]{4}{*}{ Senior } & Poor & 551 & 27,4 & Senior & Poor & 805 & 35,6 \\
\hline & Good & 1144 & 57,0 & & Good & 1173 & 51,9 \\
\hline & Very good & 313 & 15,6 & & Very good & 284 & 12,6 \\
\hline & Total & 2008 & 100,0 & & Total & 2262 & 100,0 \\
\hline \multirow[t]{4}{*}{ Old } & Poor & 430 & 32,5 & Old & Poor & 822 & 43,0 \\
\hline & Good & 765 & 57,8 & & Good & 952 & 49,8 \\
\hline & Very good & 128 & 9,7 & & Very good & 136 & 7,1 \\
\hline & Total & 1323 & 100,0 & & Total & 1910 & 100,0 \\
\hline
\end{tabular}




\section{Correlation between SRH (3 groups) and HDL-C (the dependents) and various independent factors}

A shown in Table 2, SRH correlated positively $(\mathrm{p}<0.001)$ with HDL-C, number of friends, physical activity, length of education, and intake frequency of fruit/berries, fruit juice, and raw vegetables, but negatively $(p<0.001)$ with age group, body mass index (BMI), LDL-C, triglycerides, Pain and Mood indices, smoking, and chronic diseases.

HDL-C correlated positively with sex and age, length of education, physical activity, and intake frequency of fruit/berries, vegetables and alcohol, but negatively with BMI, LDL-C and triglycerides, smoking and some chronic diseases (diabetes and CVD).

Table 2. Correlation between various independent variables and the dependent variables SRH (3 groups) and HDL-C in the whole material

\begin{tabular}{|c|c|c|c|c|c|}
\hline \multirow{2}{*}{\multicolumn{2}{|c|}{ Independent variable }} & \multicolumn{2}{|c|}{ Dependent variable $=\mathrm{SRH}$} & \multicolumn{2}{|c|}{ Dependent variable $=$ HDL-C } \\
\hline & & Spearmans $\mathbf{r s}_{\mathrm{s}}$ & $\mathbf{N}$ & Spearmans $\mathbf{r}_{\mathrm{s}}$ & $\mathbf{N}$ \\
\hline \multicolumn{2}{|c|}{ Sex $^{1}$} & $-0,046$ & 17794 & 0,398 & 17794 \\
\hline \multicolumn{2}{|l|}{ Agegroup } & $-0,252$ & 17794 & 0,136 & 17794 \\
\hline \multicolumn{2}{|c|}{ Body Mass Index $\left(\mathrm{kg} / \mathrm{m}^{2}\right)$} & $-0,166$ & 17738 & $-0,361$ & 17738 \\
\hline \multicolumn{2}{|c|}{ Time since last food intake } & $-0,042$ & 17665 & $-0,008$ & 17665 \\
\hline \multirow[t]{3}{*}{ Serum lipids } & $\mathrm{HDL}-\mathrm{C}(\mathrm{mmol} / \mathrm{L})$ & 0,102 & 17794 & 1,000 & 17794 \\
\hline & LDL-C(mmol/L) & $-0,079$ & 17794 & $-0,027$ & 17794 \\
\hline & TG (mmol/L) & $-0,159$ & 17794 & $-0,520$ & 17794 \\
\hline \multicolumn{6}{|c|}{ Psycho.social factors: } \\
\hline \multicolumn{2}{|c|}{ Number of good friends } & 0,169 & 15974 & 0,077 & 15974 \\
\hline \multicolumn{2}{|c|}{ Pain index ${ }^{2}$} & $-0,442$ & 12315 & 0,005 & 12315 \\
\hline Mood index ${ }^{3}$ & & $-0,398$ & 15716 & 0,017 & 15716 \\
\hline \multicolumn{2}{|l|}{ Years at school } & 0,291 & 17387 & 0,057 & 17387 \\
\hline \multicolumn{6}{|l|}{ Lifestyle factors: } \\
\hline \multicolumn{2}{|l|}{ Smoking 4} & $-0,138$ & 12353 & $-0,088$ & 12353 \\
\hline \multicolumn{2}{|l|}{ Alcohol intake ${ }^{5}$} & 0,000 & 17711 & 0,109 & 17711 \\
\hline \multicolumn{2}{|l|}{ Physical activity ${ }^{6}$} & 0,181 & 16809 & 0,140 & 16809 \\
\hline \multicolumn{6}{|l|}{ Diet items?: } \\
\hline \multicolumn{2}{|l|}{ Fruit/berries } & 0,091 & 17485 & 0,078 & 17485 \\
\hline \multicolumn{2}{|l|}{ Fruit juice } & 0,115 & 16887 & 0,011 & 16887 \\
\hline \multicolumn{2}{|l|}{ Raw vegetables } & 0,139 & 17411 & 0,105 & 17411 \\
\hline \multicolumn{6}{|l|}{ Chronic diseases: } \\
\hline \multicolumn{2}{|l|}{ Diabetes $^{8}$} & $-0,147$ & 17386 & $-0,080$ & 17386 \\
\hline \multicolumn{2}{|c|}{$\mathrm{CVD}^{9}$} & $-0,232$ & 17792 & $-0,038$ & 17792 \\
\hline \multicolumn{2}{|c|}{ Pulmonary diseases ${ }^{10}$} & $-0,127$ & 14586 & 0,011 & 14586 \\
\hline
\end{tabular}

$\mathrm{P}<0.001$ for all correlations, except those shown in bold. Note that the number of subjects varies due to incomplete data obtained in the questionnaire.

${ }^{1}$ Men=1; women=2

2 Musculoskeletal pain score, with 6 levels indicating increasing complaints (see Methods).

${ }^{3}$ Psychological distress score, with 6 levels indicating increasing complaints (see Methods.)

${ }^{4}$ Never smoked $=0$; current smoker $=1$.

${ }^{5}$ Alcohol (type unspecified) intake frequency: Group 0: $\leq 2-3$ times/week; group 1: >2-3 times/week.

${ }^{6}$ Light physical activity at spare time, with 4 alternatives (see Methods).

${ }^{7}$ Group $0=$ Intake frequency $\leq 1$ per month; group $1=$ more than1-3 times per month.

${ }^{8}$ Group $0=$ not diabetes, group $1=$ Diabetes.

${ }^{9}$ Group $0=$ No myocardial infarction or angina pectoris or stroke; group $1=$ one or more of these diseases.

10 Group $0=$ No rhinitis or asthma or chronic bronchitis; group $1=$ one or more of these diseases. 
Table 3. Associations between self-rated health (dependent) and HDL-C in four age groups of men and women, as influenced by covariates ( Odds ratio (OR) and $95 \% \mathrm{CI}^{1}$ )

\begin{tabular}{|c|c|c|c|c|c|c|c|c|}
\hline & \multicolumn{4}{|c|}{ Men } & \multicolumn{4}{|c|}{ Women } \\
\hline & \multirow[b]{2}{*}{ Agegroup } & \multirow[b]{2}{*}{$\begin{array}{l}\text { OR for } \\
\text { good } \\
\text { health }\end{array}$} & \multicolumn{2}{|c|}{$\begin{array}{c}95,0 \% \text { C.I. for odds } \\
\text { ratio }\end{array}$} & \multirow[b]{2}{*}{ Agegroup } & \multirow[b]{2}{*}{$\begin{array}{l}\text { OR for } \\
\text { good health }\end{array}$} & \multicolumn{2}{|c|}{$\begin{array}{c}95,0 \% \text { C.I. for odds } \\
\text { ratio }\end{array}$} \\
\hline & & & $\begin{array}{c}\text { Lower } \\
\text { Limit }\end{array}$ & $\begin{array}{l}\text { Upper } \\
\text { Limit }\end{array}$ & & & $\begin{array}{c}\text { Lower } \\
\text { Limit }\end{array}$ & $\begin{array}{l}\text { Upper } \\
\text { Limit }\end{array}$ \\
\hline \multicolumn{9}{|l|}{ HDL-C only } \\
\hline & Young & 4,94 & 2,63 & 9,29 & Young & 3,58 & 2,46 & 5,21 \\
\hline & Middle-aged & 2,25 & 1,63 & 3,09 & Middle-aged & 2,81 & 2,23 & 3,53 \\
\hline & Senior & 2,12 & 1,58 & 2,86 & Senior & 2,28 & 1,84 & 2,82 \\
\hline & Old & 1,87 & 1,37 & 2,54 & Old & 1,61 & 1,31 & 1,99 \\
\hline \multicolumn{9}{|c|}{ HDL-C+Number of friends } \\
\hline & Young & 4,87 & 2,51 & 9,45 & Young & 2,94 & 1,98 & 4,35 \\
\hline & Middle-aged & 2,09 & 1,50 & 2,92 & Middle-aged & 2,47 & 1,95 & 3,13 \\
\hline & Senior & 2,03 & 1,47 & 2,79 & Senior & 2,23 & 1,78 & 2,79 \\
\hline & Old & 1,53 & 1,08 & 2,19 & Old & 1,71 & 1,32 & 2,20 \\
\hline \multicolumn{9}{|l|}{ HDL-C+ Pain² } \\
\hline & Young & 3,42 & 1,80 & 6,48 & Young & 3,31 & 2,25 & 4,88 \\
\hline & Middle-aged & 2,07 & 1,49 & 2,87 & Middle-aged & 2,49 & 1,97 & 3,16 \\
\hline & Senior & 2,02 & 1,48 & 2,78 & Senior & 2,14 & 1,72 & 2,67 \\
\hline & Old & 1,74 & 1,27 & 2,39 & Old & 1,61 & 1,29 & 2,00 \\
\hline \multicolumn{9}{|c|}{ HDL-C+ Birthplace ${ }^{3}$} \\
\hline & Young & 4,37 & 2,31 & 8,26 & Young & 3,11 & 2,13 & 4,54 \\
\hline & Middle-aged & 1,97 & 1,43 & 2,71 & Middle-aged & 2,54 & 2,02 & 3,21 \\
\hline & Senior & 2,05 & 1,52 & 2,76 & Senior & 2,26 & 1,83 & 2,80 \\
\hline & Old & 1,87 & 1,38 & 2,55 & Old & 1,62 & 1,31 & 1,99 \\
\hline \multicolumn{9}{|c|}{ HDL-C+Smoking 4} \\
\hline & Young & 4,24 & 2,15 & 8,36 & Young & 3,80 & 2,51 & 5,76 \\
\hline & Middle-aged & 1,74 & 1,21 & 2,49 & Middle-aged & 2,95 & 2,24 & 3,87 \\
\hline & Senior & 1,77 & 1,23 & 2,56 & Senior & 2,19 & 1,69 & 2,83 \\
\hline & Old & 2,93 & 1,69 & 5,06 & Old & 1,52 & 1,17 & 1,97 \\
\hline \multicolumn{9}{|c|}{ HDL-C and Mood 5} \\
\hline & Young & 4,02 & 2,12 & 7,60 & Young & 3,26 & 2,20 & 4,81 \\
\hline & Middle-aged & 2,04 & 1,47 & 2,82 & Middle-aged & 2,72 & 2,15 & 3,46 \\
\hline & Senior & 1,98 & 1,45 & 2,69 & Senior & 2,27 & 1,82 & 2,83 \\
\hline & Old & 1,83 & 1,33 & 2,53 & Old & 1,60 & 1,29 & 1,99 \\
\hline \multicolumn{9}{|c|}{ HDL-C + Alcohol use ${ }^{6}$} \\
\hline & Young & 4,94 & 2,63 & 9,30 & Young & 3,75 & 2,56 & 5,48 \\
\hline & Middle-aged & 2,41 & 1,74 & 3,33 & Middle-aged & 2,89 & 2,29 & 3,64 \\
\hline & Senior & 2,07 & 1,54 & 2,80 & Senior & 2,22 & 1,79 & 2,75 \\
\hline & Old & 1,84 & 1,34 & 2,54 & Old & 1,57 & 1,26 & 1,94 \\
\hline
\end{tabular}




\begin{tabular}{|c|c|c|c|c|c|c|c|c|}
\hline & \multicolumn{4}{|c|}{ Men } & \multicolumn{4}{|c|}{ Women } \\
\hline & \multirow[b]{2}{*}{ Agegroup } & \multirow[b]{2}{*}{$\begin{array}{l}\text { OR for } \\
\text { good } \\
\text { health }\end{array}$} & \multicolumn{2}{|c|}{$\begin{array}{l}95,0 \% \text { C.I. for odds } \\
\text { ratio }\end{array}$} & \multirow[b]{2}{*}{ Agegroup } & \multirow[b]{2}{*}{$\begin{array}{l}\text { OR for } \\
\text { good health }\end{array}$} & \multicolumn{2}{|c|}{$\begin{array}{c}95,0 \% \text { C.I. for odds } \\
\text { ratio }\end{array}$} \\
\hline & & & $\begin{array}{l}\text { Lower } \\
\text { Limit }\end{array}$ & $\begin{array}{l}\text { Upper } \\
\text { Limit }\end{array}$ & & & $\begin{array}{l}\text { Lower } \\
\text { Limit }\end{array}$ & $\begin{array}{l}\text { Upper } \\
\text { Limit }\end{array}$ \\
\hline \multicolumn{9}{|c|}{ HDL-C + Diseases ${ }^{7}$} \\
\hline \multicolumn{9}{|c|}{ HDL-C + Pulmonary disease } \\
\hline & Young & 4,62 & 2,44 & 8,72 & Young & 3,66 & 2,50 & 5,36 \\
\hline & Middle-aged & 2,18 & 1,58 & 3,02 & Middle-aged & 2,88 & 2,27 & 3,65 \\
\hline & Senior & 2,02 & 1,49 & 2,75 & Senior & 2,10 & 1,69 & 2,62 \\
\hline & Old & 1,94 & 0,96 & 3,94 & Old & 1,62 & 1,31 & 2,00 \\
\hline \multicolumn{9}{|l|}{ HDL-C +CVD } \\
\hline & Young & 4,92 & 2,61 & 9,26 & Young & 3,72 & 2,56 & 5,41 \\
\hline & Middle-aged & 2,22 & 1,62 & 3,05 & Middle-aged & 2,87 & 2,28 & 3,62 \\
\hline & Senior & 2,01 & 1,49 & 2,71 & Senior & 2,26 & 1,83 & 2,80 \\
\hline & Old & 1,65 & 1,21 & 2,26 & Old & 1,50 & 1,21 & 1,86 \\
\hline \multicolumn{9}{|l|}{ HDL-C +Diabetes } \\
\hline & Young & 4,56 & 2,41 & 8,61 & Young & 3,38 & 2,30 & 4,95 \\
\hline & Middle-aged & 2,27 & 1,64 & 3,15 & Middle-aged & 2,74 & 2,17 & 3,48 \\
\hline & Senior & 1,92 & 1,42 & 2,59 & Senior & 2,18 & 1,75 & 2,70 \\
\hline & Old & 1,71 & 1,25 & 2,34 & Old & 1,55 & 1,25 & 1,93 \\
\hline \multicolumn{9}{|c|}{ HDL-C +Intake of Fruit/ berries ${ }^{8}$} \\
\hline & Young & 5,03 & 2,64 & 9,61 & Young & 3,59 & 2,44 & 5,27 \\
\hline & Middle-aged & 2,11 & 1,53 & 2,91 & Middle-aged & 2,72 & 2,16 & 3,43 \\
\hline & Senior & 2,19 & 1,62 & 2,96 & Senior & 2,34 & 1,88 & 2,91 \\
\hline & Old & 1,81 & 1,32 & 2,48 & Old & 1,55 & 1,25 & 1,93 \\
\hline \multicolumn{9}{|c|}{ HDL-C + Years at school } \\
\hline & Young & 3,77 & 1,97 & 7,23 & Young & 2,68 & 1,81 & 3,96 \\
\hline & Middle-aged & 1,84 & 1,33 & 2,55 & Middle-aged & 2,30 & 1,82 & 2,92 \\
\hline & Senior & 1,86 & 1,38 & 2,52 & Senior & 1,95 & 1,57 & 2,42 \\
\hline & Old & 1,62 & 1,18 & 2,22 & Old & 1,48 & 1,19 & 1,83 \\
\hline \multicolumn{9}{|c|}{ HDL-C + Adiposity ${ }^{9}$} \\
\hline & Young & 4,09 & 2,14 & 7,79 & Young & 2,79 & 1,90 & 4,10 \\
\hline & Middle-aged & 2,11 & 1,53 & 2,93 & Middle-aged & 2,28 & 1,80 & 2,90 \\
\hline & Senior & 1,83 & 1,35 & 2,47 & Senior & 1,98 & 1,59 & 2,46 \\
\hline & Old & 1,73 & 1,26 & 2,37 & Old & 1,49 & 1,20 & 1,84 \\
\hline \multicolumn{9}{|c|}{ HDL-C +Physical Activity ${ }^{10}$} \\
\hline & Young & 4,42 & 2,30 & 8,51 & Young & 2,80 & 1,88 & 4,17 \\
\hline & Middle-aged & 1,78 & 1,27 & 2,48 & Middle-aged & 2,60 & 2,05 & 3,29 \\
\hline & Senior & 1,88 & 1,38 & 2,56 & Senior & 2,12 & 1,70 & 2,64 \\
\hline & Old & 1,59 & 1,16 & 2,19 & Old & 1,42 & 1,14 & 1,77 \\
\hline
\end{tabular}

$\mathrm{P}<0.001$ for all calculations, except those shown in bold.

${ }^{1}$ All analyses are adjusted for time since last food intake, and use of cholesterol lowering drugs

${ }^{2}$ Musculoskeletal pains, dichotomized: group $0=$ no pain; group $1=$ pain located at one or more places (see Methods)

${ }^{3}$ Born in industrialized country (i.e. Europe or North-America) =group 0; developing country= 1 (i.e. Middle- or South-America, Asia, or Africa) 
${ }^{4}$ Never smoked $=0$; current smoker $=1$.

${ }^{5}$ Psychological distress factors, dichotomized: group $0=$ no complaints; group1= one or more complaints (see Methods)

${ }^{6}$ Alcohol (unspecified) intake frequency; group 0: $\leq 2-3$ times/week; group 1: >2-3 times/week

${ }^{7}$ Group $0=$ Without disease; group $2=$ with one or more disease $(\mathrm{CVD}=$ angina pectoris or myocardial infarction or stroke; pulmonary diseases: rhinitis or asthma or chronic bronchitis).

${ }^{8}$ Group $0=$ intake frequency of these diet items $\leq 1$ per month; group 1: $>1-3$ times per month.

${ }^{9}$ Group $0=$ Body mass index $\left(\mathrm{kg} / \mathrm{m}^{2}\right)<30$; group $1: \geq 30 \mathrm{~kg} / \mathrm{m}^{2}$

${ }^{10}$ Light physical activity at spare time, with 4 alternatives: no physical activity, $<1 \mathrm{~h} /$ week, $1-2 \mathrm{~h} /$ week, $\geq 3 \mathrm{~h} /$ week.

\section{Serum lipid values by sex and age group}

The concentration of serum lipids in the four age groups of the present study is shown in Figure 1. Note that different age cohorts appear on the abscissa; and that lines are used only to identify the type of lipids. In men (top panel) LDL- and HDL-cholesterol, as well as TG concentration increased from the young (30 years) to the middle age group (40 and 45 years). HDL-C continued to increase until the old age group (75-76 years) and LDL-C until the senior age group (59-60 years), whereas TG decreased from the middle age group to the old. In women (bottom panel) the serum concentration of all these lipids increased with increasing age group. Significant differences are indicated. Since, in general, LDL-C increased more than HDL-C, the HDL/LDL cholesterol ratio decreased with increasing age group (Rs $=-0,141$, $\mathrm{p}<0,001)$ and accordingly, the total cholesterol/HDL-C ratio increased with increasing age group (Rs $=0,124$, $\mathrm{p}<0,001)$.

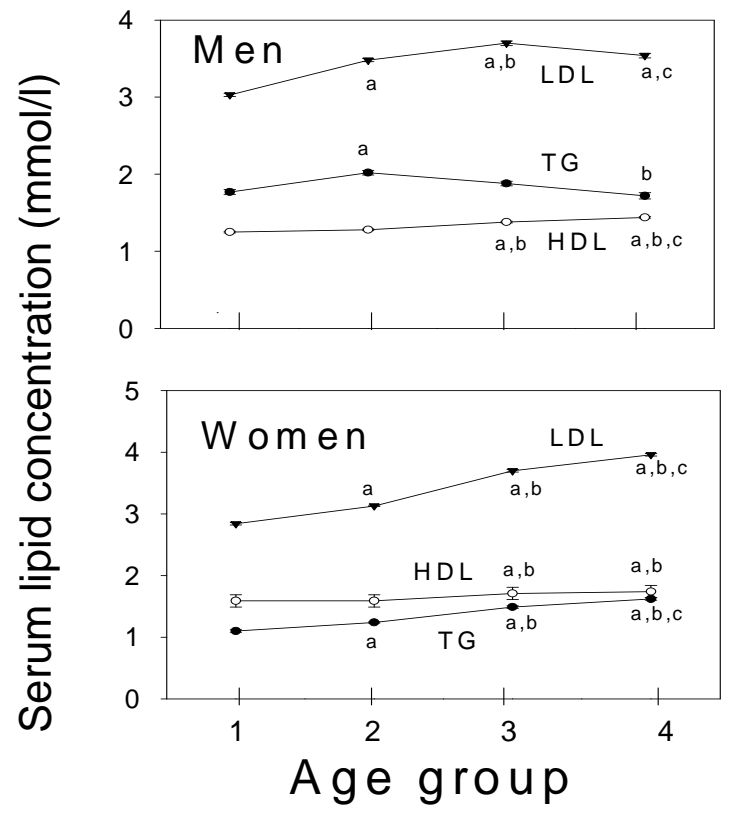

Figure 1. Serum lipid values by sex and age group. Age group 1=young (30 years old); $2=$ middle-aged (40 plus 45 years); $3=$ seniors (59-60 years); $4=$ old (75-76 years). Note that different age cohorts appear on the abscissa; the lines are used to clarify type of lipids. Mean values \pm SEM. Number of subjects in the four age groups was for men: 1786 (young), 2816 (middle-aged), 2008 (seniors) and 1323 (old). Corresponding numbers for women: 2177, 3512, 2262 and 1910. a) $\mathrm{p}<0.001$ vs. young; b) p<0.001 vs. middle-aged; c) p <0.001 vs. seniors.
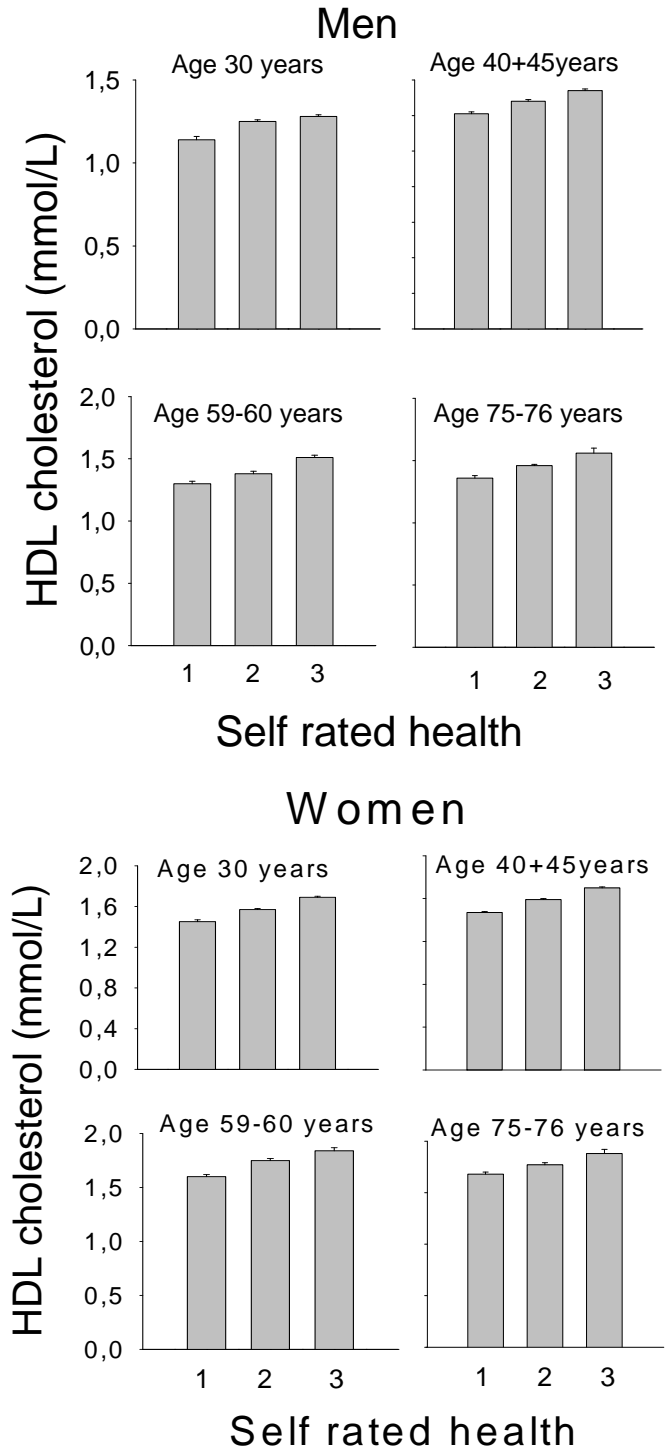

Figure 2. A. Serum HDL-cholesterol concentration in four age groups of men, as related to self-rated health. Mean values \pm SEM, which were often too small to be shown graphically. Number of subjects in the three health groups: Young: 171 (poor), 1117 (good), 498 (very good). Corresponding numbers for middle-aged: 567, 1638, 611; for seniors: 551, 1144, 313, and for old 430, 765, 128. Correlation coefficients (Spearman) between SRH and HDL-C in the four age groups were: $0.120,0.148,0.184$ and $0.156(p<0.001$ for all). B. Serum HDL cholesterol concentration in four age groups of women, as related to self-rated health. Mean values \pm SEM, which were often too small to be shown graphically. Number of subjects in the three health groups was: Young: 316 (poor), 1204 (good), 657 (very good). 
Corresponding numbers for middle-aged: 781, 1883, 848, for seniors: 805, 1173, 284, and for old 822, 952, 136. Correlation coefficients (Spearman) between SRH and HDL-C in the four age groups were: $0.210,0.204,0.198$ and $0.131(\mathrm{p}<0.001$ for all).

\section{Associations between SRH and HDL-C, adjusting for covariates}

In logistic regression (Table 3), SRH was entered as the dichotomized dependent variable and HDL-C as the independent variable to be investigated. The calculations were performed on each sex and age group separately. In each analysis, time since food intake and use of cholesterol lowering drugs were controlled for. Not including other possible confounders, the odds ratios for good health in men with high HDL-C were 4.94, 2.25, 2.12 and 1.87 going from young to old age (Table 3 ), i.e. an odds ratio about twice as high in young men as compared with the other age groups $(p<0.05$ for age group 1 vs. the other groups). In women, the age related odds ratio pattern was similar: $3.58,2.81,2.28$, and 1.61 . In the whole material, $1 \mathrm{mmol} / \mathrm{L}$ increase in HDL-C increased the odds for reporting good health by 2.27 (2.06-2.50; $\mathrm{p}<0.001)$, when adjusting for sex, age group, time since food intake and use of cholesterol lowering drugs. When including one more of the possible confounders, the sex and age group pattern was in general maintained, but the odds ratios were somewhat attenuated.

\section{DISCUSSION}

The present study confirms that there is a positive association between self-rated health and serum HDL cholesterol concentration, as previously reported in elderly subjects [8]. Our study extends the previous observation by demonstrating a positive relationship in both sexes and in several age groups. Indeed, the association between HDL-C and SRH seemed to be strongest in the young age groups, clearly contrasting the 3 older age groups. How and why the observed HDL-C vs. SRH association exists, is not apparent, but might in part be attributed to the fact that both SRH and HDL-C are both associated with a third factor. Among such factors we have considered physical activity, body mass index, dietary factors, length of education, immigrant status, chronic diseases as well as factors related to pain and mood. The present finding that the strength of the association between SRH and HDL-C was somewhat attenuated when controlling for many of these factors would seem in support of this contention. However, a significant association prevailed after several adjustments, suggesting a consistent relationship independent of the confounding factors which were introduced.

Hypothetically, the apparent age related decrease in the strength of association between SRH and HDL-C could in part be explained by the difference in exposure time of factors influencing SRH. In young people, some negative factors may not yet have had time to severely or permanently influence health. For example, the complaints estimated by the Pain and
Mood indices would have had different exposure time in young and older people. It should also be kept in mind that the four age groups represent different cohorts of people, implying group differences other than age per se. Apparently, factors not adjusted for in the present work might be involved, since the age group related difference in the SRH vs. HDL-C association persisted in spite of controlling for a large number of factors.

\section{Lifestyle factors}

It is well known that physical activity is associated with elevated levels of HDL-C $[13,14]$, and also with good health [15]. It is, however, hard to appreciate what could be the cause and effect in this association. Obviously, good health is a prerequisite for engaging in physical activity, whilst, on the other hand, physical activity may promote good health. In any instance, also in the present study there was a consistent positive association between physical activity and both HDL-C and SRH, observed in both sexes and in all four age groups. However, inclusion of physical activity did not have a major influence on the SRH vs. HDL-C association.

An inverse relationship between HDL-C and smoking [16] and positive association between HDL-C and alcohol intake [17] have been well established, and the present data are in accordance with earlier reports. However, introducing smoking and alcohol intake into the logistic regression model had only a modest effect, suggesting only a minor influence on the positive association between SRH and HDL-C.

In the bivariate analyses of the present material there was a moderate positive association between SRH and intake frequency of fruit/berries and vegetables, but these diet items did not affect the HDL-C vs. SRH association. We may assume that the positive associations between SRH and various diet items in part may be attributed to a clustering of health related behaviour factors [18].

\section{Body mass index}

It is well established that overweight reduces HDL-C, and it would seem easy to conceive that overweight or obese people also might have a low self-esteem and a low rating of their health [19]. Our results corroborate earlier reports showing an inverse association between body mass index and both SRH [20] and HDL-C [21]. However, including body mass index as an additional independent factor had only a small effect on the HDL-C vs. SRH associations except in young men and women, where the effect was appreciable. This is in line with the contention that the impact of lifestyle factors may be different in old and young subjects.

\section{Length of education}

Length of education might increase the knowledge of how to improve health through increased knowledge of the effect of various lifestyle factors [22]. In accordance with this suggestion, there was a positive correlation between length of education 
and physical activity Rs $=0.13 \quad(\mathrm{p}<0.001)$. A confounding effect of this variable is indicated by a weakening of the odds ratio for good health with increasing HDL-C when this factor was added.

\section{Chronic diseases}

It would be anticipated that the presence of chronic diseases would give generally low ratings of health, and this contention was corroborated in the present material. In addition, some lifestyle conditions and diseases may be causally related to the serum lipids, such as, diabetes 2 , and cardiovascular diseases $[22,23]$. In accordance with this, the HDL-C concentration was lower in subjects with, than without, a history of these diseases (results not shown). Each of several chronic diseases, i.e. diabetes, cardiovascular diseases (myocardial infarction, angina pectoris, and stroke), pulmonary diseases (asthma, rhinitis, and chronic bronchitis) was negatively associated with HDL-C. Including these chronic diseases into the logistic regression model did not, however, attenuate the HDL-C vs. SRH association much. Interestingly, the positive association between SRH and HDL-C was found also within groups of subjects with a history of chronic diseases (results not shown). Thus, it would appear that the presence of chronic illnesses only partially explains the association between HDL-C and SRH.

\section{Time since food intake}

The fact that the blood samples were not obtained in the fasting state is a limitation in the present study, due to a possible postprandial increase, especially in the serum triglyceride concentration. However, in the questionnaire there is a question about time since the last meal, and controlling for this variable did not affect the odds ratio for the association between HDL-C and SRH (results not shown). Surprisingly, even the association between serum triglycerides and SRH was not much affected by time since food intake.

In view of the positive association between HDL-C and self rated health, it might be questioned whether the subjects knew their serum lipid values, and the effect they might have on their health, and thereby influence their health rating. There is no direct variable in the questionnaire elucidating this question. However, we would assume that due to the general health information in Norway, many of the respondents knew their total cholesterol value, but probably not their HDL-C or LDL-C values. One exception could be patients with hyperlipemia. Therefore, we split the material into a "high" and a "low" lipid group, using total cholesterol $=5 \mathrm{mmol} / \mathrm{L}$ and triglycerides $=1.7 \mathrm{mmol} / \mathrm{L}$ as cut-off values. A highly significant association between HDL-C and SRH persisted within both the "low" and the "high" lipid groups. Additionally, controlling for the use of cholesterol lowering drugs did not have a major influence on the outcome. Nevertheless, in all logistic regression analyses we adjusted for time since food intake and use of cholesterol lowering drugs

\section{Immigrants from developing countries}

The explanations behind the negative health ratings associated with being born in a developing country are not apparent. Conceivably, there might have been socio-economic problems as regards adaptation to the Norwegian way of living, in adjusting their traditional dietary habits, and possibly difficulties in correctly interpreting the question about health. Additionally, some of them may be refugees and suffer from post war stress. In any instance, the negative association between birthplace and SRH did not affect the SRH vs. HDL-C association much.

Thus, in this relatively large material a consistent association between SRH and HDL-C was demonstrated irrespective of sex and age, and after controlling for Pain and Mood indices, physical activity level, length of education, birthplace, body mass index, and many chronic diseases. Based on the present material it would appear that subjects with good self-rated health have high serum HDL-C concentration, are well educated with a high physical activity level, and not unexpectedly, little pain and good moods. Inclusion of a number of factors in the analyses had a moderating effect on the association between SRH and HDL-C, but did not eliminate the relationship. Hypothetically, inclusion of other, as yet unknown, factors might possibly weaken the association. As inferred from the study of Jylha et al [8], white blood cell count and haemoglobin (data not available in the present material) might be among such factors.

In conclusion, there seems to be a consistent association between HDL-C and self-reported health, as observed in many age groups and in both sexes. We were not able to obliterate the association by controlling for a large number of potentially confounding factors.

\section{ACKNOWLEDGMENTS}

The data collection was conducted as part of the Oslo Health Study 2000-2001 in collaboration with the National Health Screening Service of Norway - now the Norwegian Institute of Public Health.

\section{CONFLICT OF INTEREST}

The authors have declared that no conflict of interest exists.

\section{REFERENCES}

1. Mantyselka PT, Turunen JH, Ahonen RS, Kumpusalo EA. Chronic pain and poor self-rated health. JAMA. 2003; 290:2435-2442.

2. Siedlecki SL. Predictors of self-rated health in patients with chronic nonmalignant pain. Pain Manag Nurs. 2006; 7:109-116.

3. Mossey JM, Shapiro E. Self-rated health: a predictor of mortality among the elderly. Am J Public Health. 1982; 72:800-808.

4. Trump DH. Self-rated health and health care utilization after military deployments. Mil Med. 2006; 171:662-668.

5. Emmelin M, Weinehall L, Stegmayr B, et al. Self-rated ill-health strengthens the effect of biomedical risk factors in predicting stroke, especially for men -- an incident case referent study. J Hypertens. 2003; 21:887-896.

6. Idler EL, Benyamini Y. Self-rated health and mortality: a review 
of twenty-seven community studies. J Health Soc Behav. 1997; 38:21-37.

7. Idler EL, Russell LB, Davis D. Survival, functional limitations, and self-rated health in the NHANES I Epidemiologic Follow-up Study, 1992. First National Health and Nutrition Examination Survey. Am J Epidemiol. 2000; 152:874-883.

8. Jylha M, Volpato S, Guralnik JM. Self-rated health showed a graded association with frequently used biomarkers in a large population sample. J Clin Epidemiol. 2006; 59:465-471.

9. Goldman N, Glei DA, Chang MC. The role of clinical risk factors in understanding self-rated health. Ann Epidemiol. 2004; 14:49-57.

10. Sogaard AJ, Selmer R, Bjertness E, Thelle D. The Oslo Health Study: The impact of self-selection in a large, population-based survey. Int J Equity Health. 2004; 3:3.

11. Friedewald WT, Levy RI, Fredrickson DS. Estimation of the concentration of low-density lipoprotein cholesterol in plasma, without use of the preparative ultracentrifuge. Clin Chem. 1972; 18:499-502.

12. Hernan MA, Hernandez-Diaz S, Werler MM, Mitchell AA. Causal knowledge as a prerequisite for confounding evaluation: an application to birth defects epidemiology. Am J Epidemiol. 2002; 155:176-184.

13. Wood PD, Haskell W, Klein H, et al. The distribution of plasma lipoproteins in middle-aged male runners. Metabolism 1976; 25:1249-1257.

14. Wood PD, Terry RB, Haskell WL. Metabolism of substrates: diet, lipoprotein metabolism, and exercise. Fed Proc. 1985; 44:358-363.

15. Marcus BH, Williams DM, Dubbert PM, et al. Physical activity intervention studies: what we know and what we need to know: a scientific statement from the American Heart Association Council on Nutrition, Physical Activity, and Metabolism (Subcommittee on Physical Activity); Council on Cardiovascular Disease in the Young; and the Interdisciplinary Working Group on Quality of Care and Outcomes Research. Circulation 2006; 114:2739-2752.

16. Assmann G, Schulte H, Schriewer H. The effects of cigarette smoking on serum levels of HDL cholesterol and HDL apolipoprotein A-I. Findings of a prospective epidemiological study on employees of several companies in Westphalia, West Germany. J Clin Chem Clin Biochem. 1984; 22:397-402.

17. Hulley SB, Gordon S. Alcohol and high-density lipoprotein cholesterol: causal inference from diverse study designs. Circulation 1981; 64:III-63.

18. Galan I, Rodriguez-Artalejo F, ez-Ganan L, et al. Clustering of behavioural risk factors and compliance with clinical preventive recommendations in Spain. Prev Med. 2006; 42:343-347.

19. Thommasen HV, Self B, Grigg A, et al. The relationship between self-rated health, stress, health care, overall quality of life and weight in a rural population. Eat Weight Disord. 2005; 10:e66-e69.

20. Kruger J, Bowles HR, Jones DA, et al. Health-related quality of life, BMI and physical activity among US adults $(>/=18$ years): National Physical Activity and Weight Loss Survey, 2002. Int J Obes. 2007; 31:321-327.

21. Heitmann BL. The Effects of Gender and Age on Associations Between Blood Lipid-Levels and Obesity in Danish Men and Women Aged 35-65 Years. J Clin Epidemiol. 1992; 45:693-702.

22. Molarius A, Berglund K, Eriksson C, et al. Socioeconomic conditions, lifestyle factors, and self-rated health among men and women in Sweden. Eur J Public Health. 2007;17(2):125-33.

23. Mota M, Panus C, Mota E, et al. The metabolic syndrome--a multifaced disease. Rom J Intern Med. 2004; 42:247-255. 